\title{
Choir Singing Practice and Temporal Ordering in the Elderly
}

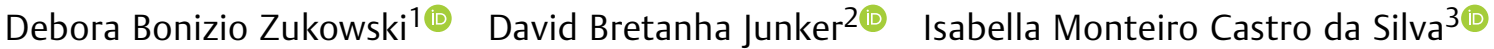 \\ Lucas Moura Viana ${ }^{4}$ Carlos Augusto Pires de Oliveira ${ }^{50}$
}

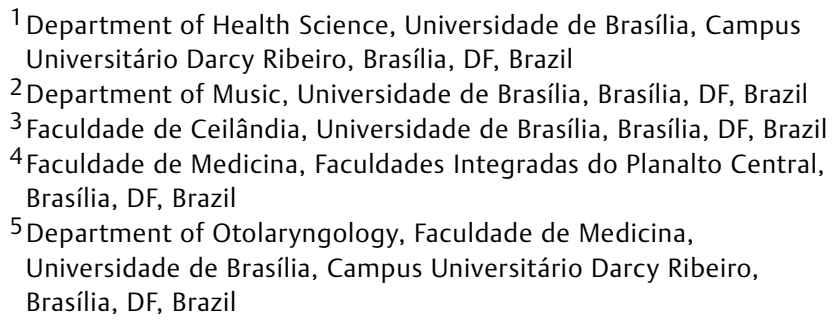

Address for correspondence Debora Bonizio Zukowski, MD, Department of Health Science, University of Brasilia, Campus Universitário Darcy Ribeiro, Brasilia, Federal District 70910-900, Brazil (e-mail: deborazuk@gmail.com).

Int Arch Otorhinolaryngol 2022;26(2):e199-e207.

\begin{abstract}
\section{Keywords}

- auditory perception

- hearing tests

- singing

- aging

Introduction The importance of temporal ordering and sequencing in the auditory system is discussed because these are considered basic functions for language.

Objective To verify the correlation between the practice of choir music and the temporal ordering in elderly with no prior formal musical experience.

Method The study design is cross-sectional. The sample consisted of 85 elderly individuals of both genders, $\geq 60$ years old, and it was composed of 43 elderly individuals with no prior formal musical experience but choir participation (research group) and 42 elderly individuals who never sang in a choir and had no music training during their life (control group). The research group was divided based on three categories of choir time. The performances of the research and control groups were compared with pitch pattern sequence (PPS), verbal condition (PPSverb), humming condition (PPShum), and duration pattern sequence (DPS) tests.

Results The mean PPShum and PPSverb showed a statistically significant difference by choir time with a different mean of PPShum between the no singing experience group $(59 \%)$ and the $>10$ years of singing experience group $(90 \%)(p=0.02)$. Regarding the averages of PPSverb, there was a statistically significant difference between the no singing experience $(23 \%)$ and $>10$ years of choir time $(54 \%)(p=0.02)$ groups. Conclusion The findings indicate a better performance in the temporal ordering of the elderly who are not formal musicians but who have choir experience in the research group in relation to those with no choir experience in the control group.
\end{abstract}

received

February 1, 2020

accepted after revision

March 23, 2021

published online

August 13, 2021
DOI https://doi.org/ 10.1055/s-0041-1733930. ISSN 1809-9777. (c) 2021. Fundação Otorrinolaringologia. All rights reserved.

This is an open access article published by Thieme under the terms of the Creative Commons Attribution-NonDerivative-NonCommercial-License, permitting copying and reproduction so long as the original work is given appropriate credit. Contents may not be used for commercial purposes, or adapted, remixed, transformed or built upon. (https://creativecommons.org/ licenses/by-nc-nd/4.0/)

Thieme Revinter Publicações Ltda., Rua do Matoso 170, Rio de Janeiro, RJ, CEP 20270-135, Brazil 


\section{Introduction}

Hearing loss is characterized by the loss of sensory and neural cells in the auditory system. In the aging process, it is called presbycusis and is already the target of many studies in audiology. ${ }^{1-6}$ Central auditory processing (CAP) refers to a series of processes involving structures of the central auditory nervous system (CANS). Studies have shown that disorders in CAP may occur in the elderly without structural damage due to changes in metabolism caused by aging. ${ }^{5,7}$ Martin et al., ${ }^{8}$ in a review of studies performed in their laboratory with a focus on the effect of age on central auditory mechanisms, identified evidences of changes resulting from aging in dichotic activities related to sensory asymmetry and difficulties in inter-hemispheric interaction. A systematic decline in temporal processing was identified after the $4^{\text {th }}$ decade of life, with a more evident acceleration after the age of 70 years old. This finding, according to the authors, may be associated with communication difficulties of the elderly characteristically in noisy environments. ${ }^{9}$ A study comparing centenaries, elderly and adults, identified a gradational degeneration of the temporal auditory processing skills over time, even with normal tonal thresholds at 250 and $500 \mathrm{~Hz} \cdot{ }^{10}$ Moreover, a study reported a relationship between poor performance in CAP and a diagnosis of Alzheimer disease. ${ }^{11}$

Auditory management processes involve the auditory pathways and the cortex. The auditory receiving area is in the Heschl gyrus, located in the middle portion of the superior temporal gyrus, in each cerebral hemisphere. ${ }^{12,13}$ The left hemisphere is important for serial ordering of temporal information. It is the dominant side for language processing for most right-handed individuals. The right hemisphere dominates the holistic functions, which are important for temporal ordering. ${ }^{14}$

The importance of temporal ordering and sequencing in the auditory system is discussed because these are considered basic functions for language. ${ }^{7,11}$ The temporal processing test includes temporal aspects of hearing, such as resolution, integration, temporal ordering, and masking. The frequency pattern test (PPS) is a test that evaluates temporal processing, being able to identify impairment in the right hemisphere, in the left hemisphere, and in the interhemispheric connections. It was considered highly sensitive for detecting brain injury. 6,15

Among the tests of auditory sequencing that showed good sensitivity for hemispheric and cortical lesions, the PPS and the duration pattern (DPS) tests where selected, as they have complementary results when investigating central functions. A study found that the DPS test was sensitive for the identification of brain lesions, since $95 \%$ of the patients with such injury had altered results. ${ }^{14}$ The authors recommend that these tests be part of any battery of central tests, as they are easy and quick to administer. ${ }^{5,14,16}$

For the Brazilian population, standardizations of DPS and PPS were performed in adults with normal hearing. ${ }^{17}$ Correct response rates ranged from 76 to $100 \%$ in the PPS test, with a mean of $91.27 \%$ of correct answers. In the DPS test, correct response rates of 83 to $100 \%$ where found, with a mean of
$95.87 \%$ of correct answers. Other studies performed with the elderly also used the reference standards found in the cited research. ${ }^{4-6}$ The study by Sanchez ${ }^{6}$ agreed with that of Musiek study, ${ }^{18}$ in which the DPS test was not influenced by mild to moderate cochlear hearing loss, and that also showed that the test can be applied in individuals with or without cochlear hearing losses to aid in the evaluation of the neural pattern for processing of nonverbal sounds. ${ }^{5,17}$

It is well-known that music can be a stimulus for changes in the responses and functionality of the auditory nervous system. ${ }^{15-18}$ Studies with musicians have shown opportunities to explore the impact of musical training on the neural structure in central and peripheral auditory processing in adults. ${ }^{19,20}$ Anatomical magnetic resonance imaging (MRI) studies in adults revealed that the Heschl gyrus of musicians has a higher volume than that of nonmusicians. ${ }^{21}$ Another study, among musicians and elderly musicians, established the relation between aging and the decline of central and peripheral auditory processing, but did not use the DPS and PPS tests. ${ }^{22}$

In the literature, there are reports that musical training can influence the results of the DPS and PPS tests. ${ }^{19}$ In Brasília, Distrito Federal, Brazil, there are many elderly choir participants with formal musical training or with no prior formal musical experience. A group of choir conductors of Brasília has $>70$ members, and many of them work with older people. These elderly individuals participate actively in choir activities, performing in concerts in theaters, churches, and in other events, requiring regular training and rehearsals with teachers trained to deal with the lay public.

It is postulated that the great productive activity of these elderly people and the verbal and nonverbal auditory stimulation they receive through the songs they sing could contribute positively to the results of the cognitive and auditory skills of this group. ${ }^{23,24}$ However, no studies that evaluated the central auditory processing of elderly choir participants laymen in music were found. Therefore, the objective of the present work is to verify the correlation between the practice of choir music and the temporal processing of elderly individuals inexperienced in formal musical activities.

The general objective of the present study is to verify the correlation between choir music and temporal ordering of the elderly with no prior formal musical experience.

The specific objective of the present study is to verify the performance of elderly choir singers in the PPS and DPS tests according to the time of participation in the choir; to verify the performance in the PPS and DPS tests of elderly individuals who do not participate in choirs; and to compare the performance in the PPS and DPS tests of elderly individuals who participate and who do not participate in choirs.

\section{Materials and Methods}

\section{Study Design}

Cross-sectional study.

\section{Ethical Considerations}

The present study had its project analyzed and approved by the Research Ethics Committee of the Faculty of Health Sciences, 
number 2,021,183. The ethical aspects that involve research in human beings was considered, as recommended by resolution CNS466 / 2012 of the National Health Council, regarding the free decision to participate or not to participate in the research. Participants signed the Free Prior Informed Consent (FPIC) and could withdraw at any time. The right to confidentiality and anonymity of the participants was guaranteed.

\section{Study Area}

The control and the research groups were recruited from a social-trade entity that promotes recreational, social, and community activities throughout the Federal District (DF). They offer physical activities, swimming, art workshops, lectures on health, recreational encounters, and choir activity, free of charge, to the elderly $\geq 60$ years old. When the authors visited these places, participants were invited to participate in the survey. Therefore, the participants had an active and independent life. The research group was also recruited from other choirs operating in the administrative region of Brasília. The present study was performed in two DF clinics: one located in the central area of Brasília, and another in the administrative region of Águas Claras. Due to the great distances between the administrative regions of the DF, the participants could choose the clinic that was closer to their residence or that was more easily accessible. The exams were performed free of charge, and participation in the research was voluntary.

\section{Study Population}

The sample consisted of 85 elderly participants, of whom 65 were female and 20 were male, $\geq 60$ years older from Brasília, Distrito Federal, Brazil. It contained choir participants (research group with 43 people) and non-choir participants (control group with 42 people). The 43 choir participants were divided into 3 categories by choir time. The initial group consisted of 19 people, 15 of whom were female and 4 were male, with 6 months to 5 years of choir participation. The intermediate group consisted of 7 people, 5 of whom were female and 2 were male, with 6 to 10 years of choir participation. The advanced group consisted of 17 people, of whom 15 were female and 2 were male, with $>10$ years of choir participation. The control group consisted of 42 people, 30 of whom were female and 12 were male, who never sang in a choir (choir time equal to 0 ) and never had music training during their lives, which is a fact that reflects the educational reality of Brazil.

In the present study only choirs that sang at least in four voices (soprano, alto, tenor, and bass were included).

The following inclusion criteria were adopted:

a) Age $\geq 60$ years old;

b) Normal hearing thresholds or cochlear hearing loss of up to 50dBNA for the average (500, 1,000, 2,000, and $4,000 \mathrm{~Hz}$ ), as recommended by the Bureau International d'AudioPhonologie (BIAP). ${ }^{25}$

c) Tympanometric curve type $A$, to exclude middle ear changes.

d) Absence of clinical history of neurological and/or psychiatric disease, collected by means of a questionnaire.

\section{Exclusion Criteria}

a) Asymmetry between the right and left ears $>10 \mathrm{dBHL}$ for the average frequencies of $500,1,000,2,000$, and $4,000 \mathrm{~Hz}$, since this makes it impossible for the 2 ears to perform similarly in the diotic stimulation.

b) Scores in the Mini Mental State Examination below expectations, as a potential source of bias.

c) Choir participants who were musicians, with formal musical training, as it would probably influence the scoring of the choir group and would mask the effect of choir participation for those without prior formal music experience. Those who did not receive formal musical training were considered as nonmusician choristers. For the purpose of the present research, formal musical training refers to a minimum of 6 years of musical instruction by a professional musician or musical educator, through technical exercises. ${ }^{22}$

\section{Period of Collection}

Data was collected starting in May and finalizing in December 2017.

\section{Method of Collection}

Data collection was performed as follows:

a) Questionnaire for mapping the profile of the participants, including age, period of participation in the choir, educational level (elementary, high school, or college), and income categorized in minimum wages.

b) Exams:

A) Meatoscopy to evaluate the presence of cerumen that could impair the results of the tests.

B) Tonal audiometry using an AC 40 audiometer (Interacoustics, Middelfart, Denmark) and a Midimate 622 audiometer (Madsen), both with two channels and calibrated according to ISO 8253 version 2010 for pure tone audiometry by air and bone conduction, ISO 8252 version 2012 for speech audiometry, following the resolution 365 of the Federal Speech Therapy Council of March 30, 2009. Pure tones were presented from 250 to $8,000 \mathrm{~Hz}$, with a maximum intensity of $120 \mathrm{~dB}$, to evaluate the auditory thresholds by air conduction, and in the frequencies of 500 to $4,000 \mathrm{~Hz}$ by bone conduction. Because it is a random heterogeneous sample of elderly participants, there is a possibility of hearing loss; therefore, the mean auditory thresholds were calculated in 2 ways: by the average airway thresholds in the frequencies of 500, 1,000 and 2,000, as recommended Lloyd et al., ${ }^{26}$ and by the average air conduction thresholds in the frequencies of $500,1,000,2,000$ and $4,000 \mathrm{~Hz}$, as recommended by the BIAP. ${ }^{25}$

C) Vocal audiometry: speech recognition index (SRI) and speech reception threshold (SRT).

D) Acoustic immittance measurements: tympanometry and acoustic reflex tests, performed with Immittances AT 235 (Interacoustics, Middelfart, Denmark). 
E) Application of the Mini Mental State Examination test ${ }^{27}$ (Annex II).

F) Frequency pattern test, ${ }^{15,28}$ using a CD presented in a booth with acoustic treatment by means of the computer connected to the auxiliary outputs of the audiometer. The test consists of the presentation of three tones of $150 \mathrm{mseg}$ and 2 intervals between the tones of $200 \mathrm{mseg}$. The tones differ in 2 frequencies: $1,122 \mathrm{~Hz}$ high frequency $(\mathrm{H})$ and $880 \mathrm{~Hz}$ low frequency $(\mathrm{L})$. The tones are combined into six different frequency patterns. Fifteen combinations of humming response and 15 naming response combinations are applied, with an interval of $\sim 6$ seconds between each combination. The tones presented in the test through the sound card of the computer to the audiometer were previously recorded on $\mathrm{CD} .^{26,27}$ The stimuli of binaural condition were presented to the participants at $50 \mathrm{~dB}$ NS, that is, $50 \mathrm{~dB}$ above the average of the tonal thresholds of the frequencies of 500, 1,000 and $2,000 \mathrm{~Hz}$ of the worst ear. Previous training was also performed, with five combinations before the start of the test. Responses are calculated as a percentage.

G) Duration pattern test, ${ }^{15}$ using a $C D$ presented in a booth with acoustic treatment by means of the computer connected to the auxiliary outputs of the audiometer. The test consists of 30 items, each with a sequence of 3 combined pure tones of $1 \mathrm{kHz}$ that differ in duration: long (L) and short (S). The long tone lasts $500 \mathrm{~ms}$, and the short tone lasts $250 \mathrm{~ms}$, and the interval between the tones is of $300 \mathrm{~ms}$. The participant was asked to name each combination after hearing it. The combination which had its three tones named correctly was considered correct. Fifteen stimuli of binaural condition were presented at $50 \mathrm{dBNS}$, that is, $50 \mathrm{~dB}$ above the average of the tonal thresholds of the 500, 1,000 and $2,000 \mathrm{~Hz}$ frequencies of the worst ear. Pretraining, with presentation of 5 groups, was performed prior to the beginning of the tests to assure the basic understanding of these tests.

\section{Statistical Analysis}

To determine which mean comparison tests were most appropriate for the present study, the Shapiro-Wilk normality test was performed, which identified that the data did not follow a normal distribution. Therefore, the Kruskall-Wallis nonparametric test was used to compare the means of the variables of interest. When this test presented significant results, the Dunn multiple comparisons test was applied on subgroups by choir time. The nonparametric measurement test, Spearman correlation, was used to identify correlations between the quantitative variables of average with three or four frequencies per ear. To measure the level of association between the profile, schooling and income, the chi-squared test of independence of variables was used. For all tests, a significance level $(\alpha)$ of $5 \%$ was considered, with a p-value $<0.05$.

\section{Results}

The research group comprised 35 women and 8 men. The control group comprised 30 women and 12 men. Therefore, 43 participants were assigned to the research group and 42 to the control group. The mean performances of the PPS humming test, verbal PPS and DPS for the control and research groups are shown in - Table 1.

The mean values of the PPS humming and PPS verbal tests were considered lower for the control group when compared with the choir group. To evaluate if the means were different based on choir time, the Kruskal-Wallis test was performed (-Table 1).

The mean humming PPS and verbal PPS showed statistically significant differences by choir time. To identify which categories presented differences, the Dunn test was performed, which presented different means for PPS humming scores between 0 years (no singing experience), with $59 \%$, and 10 years, with $90 \%(p=0.0225)$. The other categories did not present a statistically significant difference. The same occurred for the averages of verbal PPS, whose difference between the group with 0 years, with $23 \%$, and 10 years of choir time, with $54 \%(p=0.0276)$ (-Figure 1 ).

The Kruskal-Wallis mean comparison test was used to evaluate whether there was a difference in the mean of the tests between the groups by gender, and a statistically significant difference was found between the the PPSverb averages ( $33 \%$ female and $57 \%$ male; $p=0.0158$ ) and the DPS (32\% female and $55 \%$ male; $p=0.0062$ ). In these cases, the means were lower in the female group.

The mean of the tests between the education level of the groups was evaluated using the Kruskal-Wallis mean comparison test. The results indicate that there is a statistically significant mean difference for the PPSverb by schooling $(p<0.0001)$ at elementary school $(14 \%)$, high school $(30 \%)$, and college (54\%), and for the DPS by schooling $(p<0.0001)$ at the 3 levels (13; 30; and 50\%, respectively). The Dunn posthoc test was used to evaluate which categories showed differences in the means, and a statistically significant

Table 1 Distribution of the performance means (percentage), of PPShum, PPSverb and DPS tests per choir or control

\begin{tabular}{|l|l|l|l|l|}
\hline Tests & Control & Research & KW-X & $p$-value \\
\hline Mean of PPShum (\%) & 59 & 78 & 8.25 & $0.004^{*}$ \\
\hline Mean of PPSverb (\%) & 23 & 43 & 11.41 & $0.0007^{*}$ \\
\hline Mean of DPS (\%) & 28 & 40 & 3.14 & 0.0760 \\
\hline
\end{tabular}

Abbreviations: DPS, duration pattern; PPShum, frequency pattern humming condition; PPSverb, frequency pattern verbally condition. $\left(^{*}\right)$ : statistically significant. 
Table 2 Correlation between performance in PPS and DPS and averages per ear

\begin{tabular}{|c|c|c|c|c|c|c|}
\hline & PPShum & & PPSverb & & DPS & \\
\hline Variables & Spearman & p-value & Spearman & p-value & Spearman & p-value \\
\hline RE1 & $-0,21$ & $0.0334^{*}$ & - & 0.09 & -0.30 & $0.0023^{*}$ \\
\hline LE1 & -0.22 & $0.0296^{*}$ & - & 0.1745 & -0.28 & $0.0049^{*}$ \\
\hline RE2 & - & 0.0512 & - & 0.1045 & -0.27 & $0.0066^{*}$ \\
\hline LE2 & -0.22 & $0.0279^{*}$ & - & 0.0628 & -0.32 & $0.0015^{*}$ \\
\hline
\end{tabular}

Abbreviations: DPS, duration pattern; LE, left ear; RE, right ear; PPShum, frequency pattern humming condition; PPSverb, frequency pattern verbally condition.

$1=$ average with $500,1,000$ and, $2000 \mathrm{~Hz}$ thresholds; $2=$ average with $500,1,000,2,000$ and $4,000 \mathrm{~Hz}$ thresholds; $\left({ }^{*}\right)=$ statistically significant.

difference $(p<0.05)$ was found for all levels of schooling for the PPSverb and DPS tests. Thus, the higher the level of education, the higher the results of the PPSverb and DPS tests.

To evaluate whether there was a difference in the mean of the tests between the groups by income in minimum wages (mw), the Kruskal-Wallis mean comparison test was used. Although the mean of the PPShum test showed a difference between the means $(p=0.03)$, the Dunn test to identify which groups were different showed no significant difference between the means. Thus, the test is inconclusive, and it cannot be inferred that there is a difference between the means of the PPShum test. All categories of income for the PPSverb test (0 mw: 20\%; 1-3 mw: 24\%; 4-6 mw: 32\%; 7-9 mw: $28 \%)$ were different from the category $>10$ mws, which had an average performance of $62 \%(p<0.001)$. In this way, the average PPSverb is considered higher when the income is $>10$ mws. The DPS also had a statistically significant difference $(p<0.0001)$. To identify which DPS category had a mean difference, the Dunn test was performed, presenting a statistically significant difference between the category of between 1 and 3 mws, which had an average performance of $21 \%$, and the category of $>10$ mws, which had an average performance of $57 \%(p<0.0001)$.

The chi-squared association test was used to evaluate whether there was an association between the profile (research, control), schooling $(p=0.0149)$, and income $(p=0.0219)$. Thus, it is considered that there was an association between participating in choir or not and schooling and income. Also, the control group was more representative in the lower schooling and income brackets. The research group was more evenly distributed among the categories of schooling and income.

To evaluate the correlation between the results of the PPS and DPS tests with hearing loss through the average with three and four tones per ear in $\mathrm{dBHL}$, the Spearman correlation test was used. Considering a level of significance $(\alpha)$ of $5 \%$, the hypothesis that the groups are not correlated is rejected if the $\mathrm{p}$-value $<0.05$. The results are presented in - Table 2.

The mean of the right and left ears showed a weak correlation and was inversely proportional to PPS humming and DPS. The average of 4 tones of the right ear showed a significant correlation only with DPS $(p=0.0066)$. The average of four tones of the left ear presented a weak correlation and was inversely proportional to PPS humming and DPS. Thus, the hearing loss evidenced by elevated means presented a weak influence on the PPS and DPS scores.

\section{Discussion}

In its latest review, the British Society of Audiology (BSA) included aging as a cause of acquired central auditory processing disorder (CAPD). ${ }^{29}$ This reaffirms the well-known process of deterioration of the auditory processing abilities that occur with advancing age. ${ }^{2}$ The low scores in the PPS and DPS tests found in the present research ( - Table 1 ) agree with a Brazilian survey conducted with elderly people with normal hearing sensitivity, ${ }^{5}$ aged $\geq 60$ years old, using frequency pattern tests and duration. This research found a mean percentage of correct answers of $67.5 \%$ in the DPS and of $49.2 \%$ in the PPS; these results are below those found in young adults. It also found worse performance in tests with increasing age. ${ }^{5}$ Other surveys with older adults also found low performance values in these tests. ${ }^{1,6}$

Musicians present greater proficiency for auditory cognitive measures if compared with nonmusicians; specifically, better perception of speech in noise, ${ }^{30}$ auditory working memory, and temporal auditory acuity. ${ }^{31}$ One study that evaluated the effect of choir musical training on the central auditory nervous system was found. It is a longitudinal study $^{32}$ that evaluated the effect of group music lessons in the brains of adolescents from a public high school for 2 years. The curriculum involved band and choir activities. A control group received fitness training rather than music lessons. Responses to the electrophysiological examination of speech in noise were measured before and after 2 years of training. The musical group presented statistically significant differences $(p=0.0016)$ with better responses, while the fitness group did not present changes. This study was conducted in a public American school, and the music class curriculum included a group instrumental music study, and those students who chose choir also had keyboard training. The same did not happen with the choristers group analyzed in the present study, as they never received lessons in instrumental or musical theory, being exposed only to choir practice. This may justify the low performance of the choir group found in the temporal tests of the elderly of the present research ( - Table 1) when compared with musicians, in addition to the age factor that already reduces the performance of both 
groups. ${ }^{33}$ However, the values found indicate that the averages for choir time presented a statistically significant difference between the control group (choir experience time $=0$ ) and the group with choir time $>10$ years, indicating a better performance when the choir time is prolonged. Choir practice with people without prior musical knowledge is a tool that provides the development of multiple skills and competences. ${ }^{34}$ Cognitive changes have been described in choir practice with the elderly, with people without any training in music. It was noted that it was easier to prepare the repertoire due to the greater ability to concentrate and memorize the lyrics and melodies, ${ }^{23,24}$ in addition to the self-report of feelings of improvement in learning among the participating choristers. ${ }^{23}$ The benefits of singing for elderly lay people in music and even without musical gifts, however, go beyond cognitive gains such as maintaining memory. ${ }^{23,24,34}$ Pleasurable activity increases self-esteem, personal satisfaction in overcoming challenges, and social interaction, and, consequently, results in a better quality of life. ${ }^{24}$

No study was found in which only the performance of choir groups in the PPS and DPS temporal tests was evaluated. A study comparing children, between music students and non-music students ${ }^{35}$ in the performance of the PPS test, found a better performance of the children who studied music, with a statistically significant difference $(p<0.05)$. Another study compared PPS among professional singers, amateur singers, and amateur singers out of tune, ${ }^{36}$ finding a statistically significant difference between the groups. The group of professional singers presented a higher average of correct answers, followed by the group of independent amateur singers and, finally, by the group of amateur singers out of tune. Also on popular singers, through the PPS test, a study compared singers between the ages of 19 and 55 years old who play musical instruments with people who only sing. ${ }^{20}$ A statistically significant difference was found between the groups ( $p=0.028)$, with a better performance for the group that plays and sings ( mean $=95.70 \%$ ). The group that only sings had a mean of $82.30 \%$. Another study evaluated violinist musicians and nonmusicians in the PPS temporal test, ${ }^{19}$ obtaining better performance in the tests for the group of musicians. A comparison was also made between the average of the thresholds of the low and high frequencies and of the tritonal mean and PPS scores in order to observe if there was a correlation between them, observing that the lower the mean values, the higher the PPS values.

According to the American Academy of Audiology (AAA), ${ }^{37}$ the CAP test can be performed in the elderly with a lower degree of hearing loss and good ability to recognize speech using tests that are less affected by cochlear hearing loss, suggesting that the PPS is one of them. This is because the authors found that these tests are resistant to hearing loss, as long as the stimulus can be perceived by the subject. ${ }^{15,28}$

In the present study, participants with presbycusis were included. As the correlation analysis between the ear averages and the test results was weak, it was not possible to differentiate the performances among the participants with or without hearing loss. In a systematic review, four studies compared the influence of hearing loss on the DPS test; only one of them also compared the PPS test. ${ }^{38}$ The studies agreed on the results that showed no influence of the age-related hearing loss in these temporal tests, because no statistical difference was found between the results of the groups with and without hearing loss. ${ }^{1,3,4,39}$ For the standardization of 10 auditory processing tests, including the PPS and DPS tests, Humes et al. ${ }^{40}$ evaluated 38 elderly individuals and 40 young adults. The elderly group was divided into subgroups with and without age-related hearing loss. The elderly group presented worse performance than the group of young adults, regardless of whether or not they had hearing loss. The Scheffe post-hoc tests were performed to determine the contrasts of the groups, and the results showed that the group of elderly with hearing loss scored significantly worse in 5 tests. However, the PPS and DPS tests did not present a statistically significant difference in the comparison between individuals with and without hearing loss. ${ }^{40}$

Confounding factors such as educational level, income, and cognitive factors were evaluated in the present study to reduce the risk of bias. The tests in the present study showed an association of the educational level, an unconfirmed result in another study with the elderly on the effect of hearing loss in the PPS test, although with a lower number of participants. ${ }^{41}$ This shows the need for further research on this confounding factor. The variable educational level is considered in the normative studies of CAP. ${ }^{15,17,42-46}$ The BSA says that CAPD often occurs along with shortcomings in executive functions, memory, speech, and attention, and may contribute to the disorder of these systems. Therefore, the disorder may include auditory and cognitive elements. ${ }^{29}$ Some Brazilian studies excluded participants who had musical education ${ }^{17,41}$ even just for a few years and only in group, in a regular school. No justification was found for this exclusion, since international normative studies ${ }^{15,33,42-44,46-49}$ do not exclude people with musical education offered by the regular school as part of the curriculum, not characterizing it as a confounding factor. One justification would be the reality of Brazilian education, which does not usually offer music education in schools. However, in the present study, some elderly people reported having received musical education at school but were excluded because they did not participate in choir and could not go to the control group. This calls attention to the fact that, today, Brazilian public schools do not offer music education in their curriculum, not even in groups. The fact that, in the present study, the control group never had contact with music education can influence the low performance of this group.

To identify changes in cognitive functions, the MiniMental State Examination was performed as an exclusion criterion. Other studies evaluating PPS and DPS also performed this test because cognitive factors may influence the application and the temporal test results. ${ }^{4,41}$ To minimize the effect of language on processing tests, many studies have used nonverbal tests such as PPS and DPS. ${ }^{29}$

The limitations of the present research should be mentioned. The present study reflects the Brazilian reality regarding musical education and may not have external 


\title{
PPS and DPS percentage scores by choir time
}

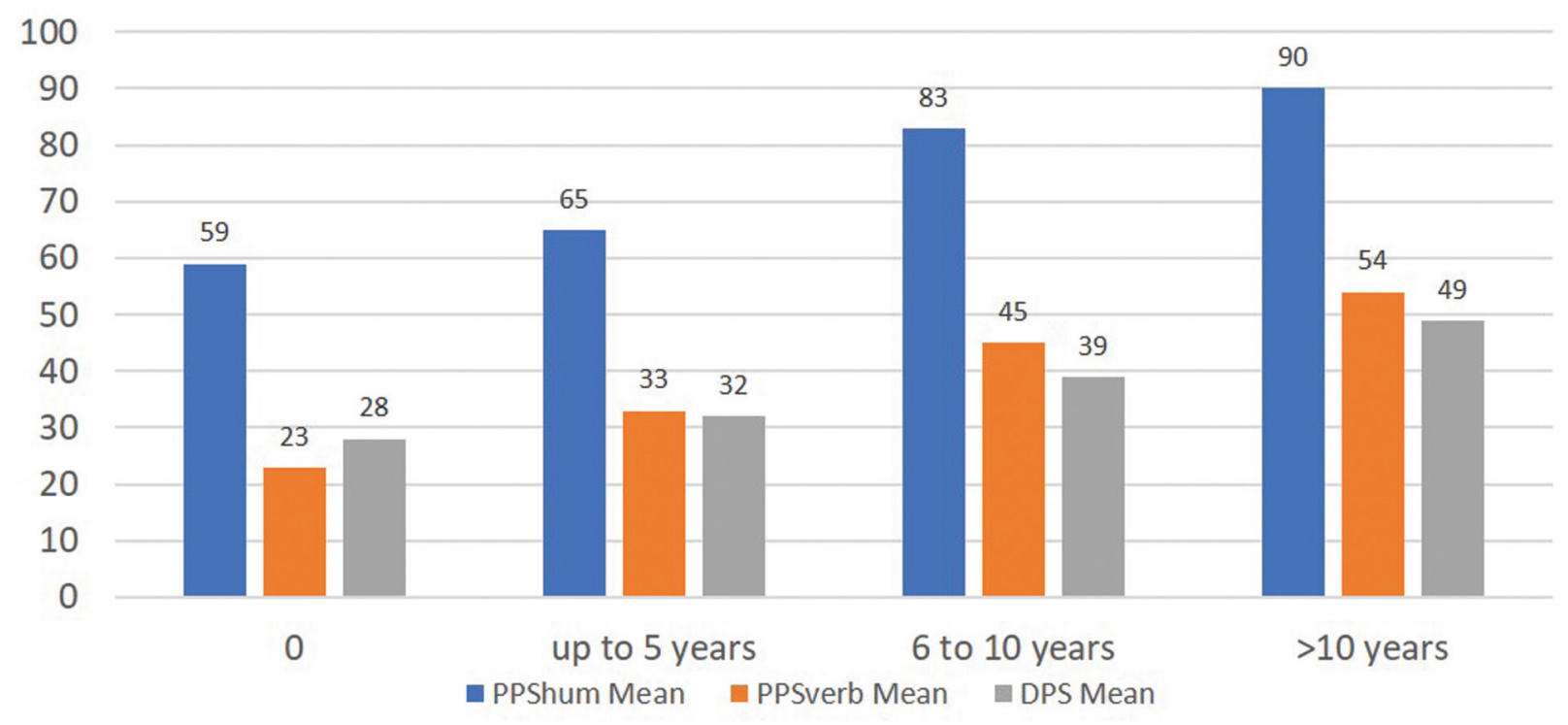

\begin{abstract}
PPShum- Picth Pattern Sequence - humming response; PPSverb - Picth Pattern Sequence - verbal response; DPS - Duration Pattern Sequence.
\end{abstract}

Fig. 1 PPS and DPS score by choir time.

validity. However, it shows the importance of musical education for these central auditory tests.

The number of presentations was 30 in binaural mode, 15 for each mode of PPS response (humming and verbally), and 15 in binaural mode for DPS. At first, the test was performed with 30 presentations for each condition, as recommended in the literature, ${ }^{50}$ but the participants complained about the time they were inside the booth, without air conditioning. Therefore, it was necessary to reduce the number of presentations. Fadel et al. ${ }^{51}$ used the pitch matching test with a sequence of 10 sound tasks, the first 5 of which were synthesized sound and, the last 5 , sound recordings of the vowel / $\mathrm{u} /$, to assess the accuracy in the reproduction of sounds. They also applied the PPS with 10 items in each ear to be able to correlate the results of the 2 tests. The authors identified interesting correlations between good vocal accuracy in the PMT and performance in the PPS test. Bamiou et $\mathrm{al}^{52}$ applied the PSS with 20 items for each ear assessed separately. Humes et al. ${ }^{40}$ does not describe the number of items evaluated but evaluated only the left ear. Parra et al. ${ }^{5}$ presents 30 items for each ear separately. Studies with the elderly using these temporal tests range from 15 to 60 presentations, in monaural or binaural mode, ${ }^{5,9,53,54} \mathrm{dem}$ onstrating that despite efforts to standardize the tests, some factors related to the sample, to the duration of the complete research protocol, to the internal temperature of the booth, or even to respiratory discomfort, makes impractical to prolong time in a soundproof booth, leading to adjustments in the test application methodology, without prejudice to the interpretation of data.
The age factor was considered without stratification, and the collection was done with active and independent elderly people, since those who did not participate in choir participated in a program for the elderly that demanded several physical, sports, and social activities and lectures during the week. A survey of the elderly with normal hearing sensitivity found that the older the age, the lower the score on the tests. ${ }^{5}$ Other studies with PPS observed the effect of aging on the central auditory nervous system. ${ }^{54}$ However, a PPS study, in which the elderly were divided into 3 groups, one from 60 to 65 years old, another from 66 to 70 years old, and the last one $\geq 71$ years old, did not find a significant difference between the groups. ${ }^{6}$

The profile of the choristers compared with the control was also a limitation of the research, since low income and non-participation in choir may be confounding factors, although the control group had the same opportunity as the choir group to choose the choir activity offered by the free service provided to the elderly but did not choose choir singing. In the present research, the profile of people who enjoy choir singing was higher in both schooling and income. Future research could clarify these preferences.

\section{Conclusion}

The findings of the present study indicate a better performance in the temporal ordering of the elderly with choir experience, in the research group, in relation to those with no choir experience in the control group, with a statistically significant difference between the group that does not 
participate in choir and the group with $>10$ years of choir for the PPS test verbal and humming condition. No statistically significant difference was found for the DPS test between choir and non-choir groups, not even for time of participation in choir among the elderly with choir experience.

\section{Funding Sources}

The authors have no funding sources to declare.

\section{Conflict of Interests}

The authors have no conflicts of interest to declare.

\section{References}

1 Azzolini VCFerreira MIDdC. Temporal auditory processing in elders. International Archives of Otorhinolaryngology, Vol 14, Iss 1, Pp 95-102. 2010:14

2 Jerger J, Chmiel R, Allen J, Wilson A. Effects of age and gender on dichotic sentence identification. Ear Hear 1994;15(04):274-286

3 Lima IMDS, Miranda-Gonsalez ECD. Efeitos da perda auditiva, escolaridade e idade no processamento temporal de idosos. Revista Cefac 2016;18(01):33-39

4 Liporaci FD, Frota SMMC. Envelhecimento e ordenação temporal auditiva. Revista CEFAC 2010;12(05):741

5 Parra VM, Iório MCM, Mizahi MM, Dos S, Baraldi G. Frequency and duration patterns tests in elderly people with normal hearing sensitivity. Rev Bras Otorrinolaringol (Engl Ed) 2004;70(04):517-523

6 Sanchez ML, Nunes FB, Barros F, Ganança MM, Caovilla HH. Auditory processing assessment in older people with no report of hearing disability. Brazilian Journal of Otorhinolaryngology 2008;74(06):896-902

7 Wong PC, Ettlinger M, Sheppard JP, Gunasekera GM, Dhar S. Neuroanatomical characteristics and speech perception in noise in older adults. Ear Hear 2010;31(04):471-479

8 Martin JS, Jerger JF. Some effects of aging on central auditory processing. J Rehabil Res Dev 2005;42(04, Suppl 2):25-44

9 Ajith KU, Sangamanatha AV. Temporal processing abilities across different age groups. Journal of the American Academy of Audiology 2011;22(01):5-12

10 Kołodziejczyk I, Szelsg E. Auditory perception of temporal order in centenarians in comparison with young and elderly subjects. Acta Neurobiol Exp (Warsz) 2008;68(03):373-381

11 Sheft S, Shafiro V, Wang E, Barnes LL, Shah RC. Relationship between auditory and cognitive abilities in older adults. PLoS One 2015;10(08):e0134330

12 Cope TE, Baguley DM, Griffiths TD. The functional anatomy of central auditory processing. Pract Neurol 2015;15(04):302-308

13 Schoeny Z, Talbott R. Testes centrais: procedimentos utilizando estímulos não-verbais. Katz J. Tratado de audiologia clínica, São Paulo: Manole; 1999:210-9

14 Musiek FE, Pinheiro ML, Wilson DH. Auditory pattern perception in 'split brain' patients. Arch Otolaryngol 1980;106(10):610-612

15 Musiek FE. Frequency (pitch) and duration pattern tests. J Am Acad Audiol 1994;5(04):265-268

16 Musiek F, Lamb L. Avaliação auditiva central: uma visão geral. Tratado de audiologia clínica Ed. 1999;4:195-209

17 Corazza MCA. Avaliação do processamento auditivo central em adultos: teste de padrões tonais auditivos de frequência e teste de padrões tonais auditivos de duração [doctoral dissertation]. São Paulo: Universidade Federal de São Paulo; 1998

18 Musiek FE, Baran JA, Pinheiro ML. Duration pattern recognition in normal subjects and patients with cerebral and cochlear lesions. Audiology 1990;29(06):304-313

19 Nascimento FM, Monteiro RAM, Soares CD, Ferreira I. Habilidades de sequencialização temporal em músicos violinistas e nãomúsicos. Int Arch Otorhinolaryngol 2010;14(02):217-224
20 Ribeiro ACM Avaliação dos aspectos temporais em cantores populares [Trabalho de conclusão de curso]: Universidade Federal de Santa Catarina; 2016

21 Seither-Preisler A, Parncutt R, Schneider P. Size and synchronization of auditory cortex promotes musical, literacy, and attentional skills in children. J Neurosci 2014;34(33):10937-10949

22 O'Brien JL, Nikjeh DA, Lister JJ. Interaction of musicianship and aging: A comparison of cortical auditory evoked potentials. Behav Neurol 2015;2015:545917. Doi: 10.1155/2015/545917

23 Rabelo TFO canto coral como prática educativo-musical na terceira idade. Colóquio Internacional Educação e Contemporaneidade. 2011:5

24 Prazeres MM, Lira LC, Lins RG, Cárdenas CJ, Melo GF, Sampaio TM. O canto como sopro da vida: um estudo dos efeitos do canto coral em um grupo de coralistas idosas. Revista Kairós Gerontologia. 2013;16(04):175-193

25 Audiometric classification of hearing impairment: recommendation 02/1 Bureau Internacional D’audio Phonologie. 1996 [Available from: http://www.biap.org/fr/recommandations/recommendations/tc-02classification

26 Lloyd LL, Kaplan H. Audiometric interpretation: a manual of basic audiometry. University Park Press; 1978

27 Folstein MF, Folstein SE, McHugh PR. "Mini-mental state". A practical method for grading the cognitive state of patients for the clinician. J Psychiatr Res 1975;12(03):189-198

28 Musiek FE, Pinheiro ML. Frequency patterns in cochlear, brainstem, and cerebral lesions. Audiology 1987;26(02):79-88

29 British Society of Audiology. Auditory processing disorder (APD) position statment and practice guidance. 2018 [Available from: www.thebsa.org.uk/resources/position-statement-practice-guidanceauditory-processing-disorder-apd/

30 Parbery-Clark A, Skoe E, Lam C, Kraus N. Musician enhancement for speech-in-noise. Ear Hear 2009;30(06):653-661

31 Parbery-Clark A, Strait DL, Anderson S, Hittner E, Kraus N. Musical experience and the aging auditory system: implications for cognitive abilities and hearing speech in noise. PLoS One 2011; 6(05):e18082

32 Tierney A, Krizman J, Skoe E, Johnston K, Kraus N. High school music classes enhance the neural processing of speech. Front Psychol 2013;4:855

33 Humes LE. Speech understanding in the elderly. J Am Acad Audiol 1996;7(03):161-167

34 Fucci Amato R. O canto coral como prática sócio-cultural e educativomusical. Opus 2007;13(01):75-96

35 Anand K, Mohan KM, Yeraguntla K. Auditory processing abilities in amateur musicians. International Journal on Disability and Human Development 2017;16(01):105-113

36 Ishii C, Arashiro PM, Pereira LD. Ordenação e resolução temporal em cantores profissionais e amadores afinados e desafinados. Pró-Fono Revista Atualização Científica 2006;18 (03):285-292

37 American Academy of Audiology. Guidelines for the diagnosis, treatment and manegment of children and adults with central auditory processing disorder. 2010 [Available from: https://audiology-web.s3.amazonaws.com/migrated/CAPD\%20Guidelines\%2082010.pdf_539952af956c79.73897613.pdf

38 Zukowski DB. Habilidades de processamento auditivo temporal em testes de padrão de frequência e duração para idosos: revisão sistemática com metanálise. In: Prática de canto coral e processamento de ordenação temporal em idosos. [dissertation]. Brasília: University of Brasília 2019:15-31

39 Gratão de Mesquita L, Desgualdo Pereira L. Processamento temporal em idosos: o efeito da habilidade de resolução temporal em tarefas de ordenação de série de sons. Rev CEFAC 2013;15(05): 1163-1169

40 Humes LE, Coughlin M, Talley L. Evaluation of the use of a new compact disc for auditory perceptual assessment in the elderly. J Am Acad Audiol 1996;7(06):419-427 
41 Lima IMdS. Miranda-Gonsalez ECd. Efeitos da perda auditiva, escolaridade e idade no processamento temporal de idosos. Revista CEFAC 2016;18(01):33-39

42 Casaprima V, Jannelli A, Lobo M, Martínez E, Lizarraga A. Obtaining normative values in the evaluation of central auditory function. Revista Medica de Rosario 2013;79(02):73-77

43 Marshall EK, Jones AL. Evaluating test data for the duration pattern test and pitch pattern test. Speech, Language and Hearing 2017;20(04):241-246

44 Neijenhuis K, Snik A, Priester G, van Kordenoordt S, van den Broek P. Age effects and normative data on a Dutch test battery for auditory processing disorders. Int J Audiol 2002;41(06):334-346

45 Saleh S, Campbell NG, Wilson WJ. The performance of South African English first and second adult speakers on a "low linguistically loaded" central auditory processing test protocol. S Afr J Commun Disord 2003;50:19-25

46 Tsang K-m. Norms for the pitch pattern sequence (PPS) test for Cantonese adults. [bachelor dissertation]. In press 2003

47 Bellis TJ, Ross J. Performance of normal adults and children on central auditory diagnostic tests and their corresponding visual analogs. J Am Acad Audiol 2011;22(08):491-500
48 Fuente A, McPherson B. Auditory processing tests for Spanishspeaking adults: an initial study. Int J Audiol 2006;45(11): 645-659

49 Majak J, Zamysłowska-Szmytke E, Rajkowska E, Śliwińska-Kowalska M. Auditory temporal processing tests - Normative data for polish-speaking adults. Med Pr 2015;66(02):145-152

50 Musiek FE. The frequency pattern test: a guide. The Hearing Journal. 2002;55(06):58

51 Fadel CBX, Ribas A, Lüders D, Fonseca VR, Cat MNL. Pitch-Matching Accuracy and Temporal Auditory Processing. Int Arch Otorhinolaryngol 2018;22(02):113-118

52 Bamiou DE, Iliadou VV, Zanchetta S, Spyridakou C. What can we learn about auditory processing from adult hearing questionnaires? J Am Acad Audiol 2015;26(10):824-837

53 Alonso R. Avaliação eletrofisiológica e comportamental do processamento auditivo (central) e treinamento auditivo em indivíduos idosos [doctoral dissertation]: Universidade de São Paulo. 2011

54 Bellis TJ, Wilber LA. Effects of aging and gender on interhemispheric function. J Speech Lang Hear Res 2001;44(02):246-263 